\section{CARCINOMA RECTI; RIGHT INGUINAL COLOTOMY.}

BY ALFRED COOPER, F.R.C.S. ENG. \&c.,

SENIOR SURGEON TO ST. MARK'S HOSPITAL FOR FISTULA AND OTHER DISEASES OF THE RECTUM.

A B00KBINDER aged fifty-six was admitted into St. Mark's Hospital for Fistula and other Diseases of the Rectum on Nov. 12th, 1892, suffering from malignant disease of the rectum. There was no history of cancer or rectal disease in the patient's family. He had enjoyed good health until four months before admission. $\mathrm{He}$ had had measles and whooping-cough when a child, but no severe illness since. He had not suffered from any previous rectal trouble, such as hæmorrhoids or fistula. The bowels had been regular all his life. There was no history of previous abdominal inflammation. About four months ago the patient noticed for the first time a constant desire to evacuate the contents of his rectum, this being the first symptom of rectal discomfort that he complained of. Since then the motions had always been very relaxed; he had not had a formed motion for the previous sixteen weeks. Two months after the first onset of these symptoms he noticed when at stool that his motion was streaked with blood of a bright-red colour. Since then he had continually passed blood when his bowels had acted, but not to any great extent. He had felt little or no pain in the rectum, the only discomfort being the constant desire to go to stool, and even when his bowels acted this feeling did not pass off. He occasionally complained of pains shooting down both thighs. As he was continually losing blood and could not obtain any relief from the constant desire to defecate he was advised to attend St. Mark's Hospital, where he was found to be suffering from carcinoma. On admission the heart and lungs were normal, and the urine was acid, clear, of sp. gr. 1020, and containing no albumen. On rectal examination adranced malignant disease was found, starting two inches above the anus. Its upper limit could not be determined as the finger could not reach above it. The growth had already invaded the surrounding tissues. On Nov. 22nd, the patient having been placed under the influence of chloroform, I made the usual incision for left inguinal colotomy, my colleague, Mr. Swinford Edwards, assisting me. Having opened the peritoneal cavity, a scarch was made for the sigmoid colon, but in vain, nor were Messrs. Goodsall and Edwards more fortunate in their attempts. There was clearly a malposition of the gut, so on Mr. Goodsall's recommendation it was determined to close the wound and to perform the operation on the right side with a view of opening the cæcum, or perhaps even the sigmoid, for it has been known to take up this position when it has failed to occupy its own. This having been done, the gut was found lying over the cæcum and firmly fixed there, so that it could not be drawn out of the wound. This being the case, the mesenteric suture was omitted, the bowel being simply stitched to the united skin and peritoneal edges by several sutures. The patient was then ordered to have a pint of milk during the next twenty-four hours.

Nov. 23rd. - The patient slept fairly well during the night; he has had no sickness; he took his milk well. The temperature is $974^{\circ}$; the pulse is 68 , regular. He states that he has a feeling of discomfort all over the abdomen, but not actual pain ; he seems very bright and in good spirits. Evening: $\mathrm{He}$ has had a very good day. The temperature is now $98.8^{\circ}$; the abdominal discomfort is much less.

24th.-He passed a very good night. He has had a pint of milk and half a pint of beef-tea within the last twenty-four hours; there has been no sickness or pain. The temperature is $982^{\circ}$; the pulse is 64 , regular. The dressings over the right wound were removed by the house surgeon, Mr. Ryall, and, the gut being distended, he incised it with scissors, where upon fluid fæces and a quantity of gas escaped. Evening The bowels have freely acted through the colotomy wound, the fæces that passed being still fluid. The patient has had a very good day. The temperature is $984^{\circ}$.

25th.-He slept well during the night ; there is no pain or sickness. The bowels have been freely relieved through the colotomy wound, the fæces being still liquid. The temperature is $984^{\circ}$; pulse 60 .

The patient made daily progress towards recovery without a bad symptom of any kind, the sutures being removed from the right colotomy wound on Nov. 27 th, and from the left, which had healed, on Nov. 29th. On Dec. 8th a right inguinal colotomy truss was applied and he was discharged from the hospital much relieved on Dec. 10th, eighteen days after the operation.

Memarks. - It has been thought worth while to record this case as an example of a somewhat rare condition occasionally met with in performing inguinal colotomy and also as showing what seems to be the best way of dealing with it. On finding the large intestine on the right side it was easy, of course, to recognise it, but less so to determine whether it was the mal-placed sigmoid or the cæcum. Time alone solved this question. Although the evacuations were always fluid when in hospital, looking as though it was the crecum which had been opened, they soon became more firm and formed, which would not have been the case had it been the beginning of the large intestine. Mr. Swinford Edwards saw the patient last on Jan. 4th, 1893, when he appeared very comfortable, though he complained a little of his rectum and of the annoyance caused by a small amount of fæces passing that way. This was unavoidable, because, as mentioned above, the gut being tightly held down, it was impossible to form a spur by means of a deep or mesenteric suture, a proceeding most necessary to ensure the full benefits of the operation. He was passing wellformed and solid motions through the artificial anus. It should be mentioned that excision of the rectum in this case was contraindicated, not only on account of the height to which the growth extended, but more especially seeing that the disease had already to some extent involved the surrounding structures.

Henrietta-street, W.

\section{ICE IN THE TREATMENT OF ACUTE PNEUMONIA.}

A COLLECTIVE REPORT.

BY THOMAS J. MAYS, M.D.,

PROFESSOR OF DISEASES OF THE CHEST IN THE PHILA DELPHIA POLY. CLINIC, VISITING PHYSICIAN TO THE RUSH HOSPITAL FOR
CONSUMPTIVES ETC.

WHATEVER its nature may be, it is quite certain that no other disease has elicited a greater number of conflicting opinions concerning its treatment than has croupous pneu. monia. Forty years ago bleeding and blistering were regarded as its specifics; but these are now, and for the last twenty years have been, scarcely thought of in this connexion. In the meantime hot poultices, aconite, veratrum viride, digitalis, quinine \&c., have taken their places, yet it is not too much to say that they have all led to disappointment and come to grief in the retort of clinical experience, and that finally the profession has gravitated to the conviction that the disease is self limited in duration, and that hence all efforts to control its course are fruitless, if not actually harmful. To be thus compelled to stand before a disease and acknowledge one's helplessness and impotency is, to say the least, an un. enviable position, but I must confess that until I became familiar with the value of local cold applications in this disease I was in hearty accord with this idea. Since then I may say that I am able to approach a case of pneumonia with a greater degree of assurance-not with the feeling, however, that we possess a specific, but with the confidence that here is an agent with which we are able to impress and circumvent the severity of the pneumonic process. I believe that cold properly applied will affect the death-rate of pneamonia as profoundly as it has affected that of typhoid fever, and, although I do not expect a rapid introduction of this measure, on account of a deep-rooted prejudice which exists against the use of cold in almost all internal diseases, I trust that the evidence which is herewith submittea will serve to commend it to the serious attention of the profession. Under the titles, "Can Croupous Pneumonia be Abater ?" and "Ice in the Treatment of Croupous Pneumonia," I contributed two papers to the Medical Ners of Sept. 24th, 1892, and Jan. 21st, 1893, respectively, in which are related three cases of pneumonia which were treated principally with applications of ice to the chest ; and since the appearance of the first paper I instituted a collective investigation on a small scale by sending a number of circulars ${ }^{2}$ to various

I Similar circulars will be cheerfully sent by mo to ang one who may apply for them. 